\title{
Using Adobe Acrobat software to facilitate global collaboration in the enterprise - Interview with Rak Bhalla of Adobe Systems Incorporated
}

\begin{abstract}
Rak Bhalla
Rak Bhalla is a senior marketing manager in the Business Productivity Business Unit at Adobe Systems Incorporated. He is responsible for developing marketing strategies and driving marketing programs for the company's desktop and server solutions software in the manufacturing industry. Bhalla has more than 20 years of domestic and international experience in manufacturing, during which he has served in diverse roles, including marketing executive, CAD technician and consultant. He possesses an extensive knowledge of both the high-level and practical challenges manufacturing professionals face while working to increase competitive advantage and bring products to market. Prior to joining Adobe, Bhalla spent 12 years at Autodesk working in several senior-level positions, where he focused on growing the company's presence in the manufacturing market. Earlier, he worked as a CAD/CAM senior applications analyst for ComputerVision/CTI, focused on technical demonstrations, consulting and training. Bhalla has a degree in Mechanical Engineering Technology from Dawson College in Montreal, Quebec, Canada.
\end{abstract}

Keywords: Acrobat, 3D, PDF, CAD, collaboration, PLM

Abstract Michael Moon interviews Rak Bhalla of Adobe Systems, discussing how the Portable Document Format and Adobe's Acrobat software family, particularly Acrobat 3D, help facilitate collaboration in a globally extended work environment.

Note: Subsequent to this interview, but prior to publication, Adobe has renamed Acrobat 3D to Acrobat 9 Pro Extended

Journal of Digital Asset Management (2008) 4, 150-157. doi:10.1057/dam.2008.23

MM: Rak, why don't we start with an introduction of you and a little bit of your background. Then we'll move on.

RB: Sure. I'm a senior marketing manager in the business productivity business unit here at Adobe. My main responsibility is driving all the different aspects of our manufacturing portfolio of products, which includes Acrobat 3D. But it also includes more products, as well — like the LiveCycle Server products.

I've been working in the manufacturing industry for about 25 years, right now — having different roles. From marketing to being a technical person and a consultant... I've gathered some extensive knowledge in highlevel and practical challenges that our manufacturing customers have faced, because I've been working with them for so long. I have been a CAD user of a variety of different CAD applications, as well.

MM: Why don't you share with us the history of Acrobat, and its current state?
RB: If you take a look at the entire Acrobat family, it spans from the standard product - or what we call Acrobat Standard - to the next level of functionality and benefits, and Acrobat Professional. Then we've got our premium offering called Acrobat 3D. That's really a superset of all the features and functionality of all our products.

Acrobat Professional - which is the most popular product right now — really caters to a very diverse populace. Whether you are a human resources person, a marketing or legal professional - even a technical CAD user you can really benefit from Acrobat Pro.

Where Acrobat 3D really adds value to our customers' workflows is an ability to share more of this 2D and 3D CAD data - along with all the other product data that's involved in engineering. It helps engineers share all this product data - including the $3 \mathrm{D}$ design and technical specifications with other people outside the engineering team. I'll drill down on the specifics a little bit later on. 
MM:Yes, Rak. If you would, just explain briefly what you mean by "product data."

RB: Sure. Product data is not just about the pretty picture and 3D CAD. Engineers work on specifications. So they've got Excel spreadsheets. They're creating Word docs. They're sending emails. They may have captured some bitmaps. All of this critical data can be lumped into a category called "product data."

As our customers are preparing their products to go to market, it's much more than just that pretty picture. Engineers want to share all of the related project information with people outside of engineering, who can consume this data in many different ways.

MM: To summarize it at this point, Acrobat 3D is really about - in many respects - moving engineered products or goods to market. It really becomes a container not just of the drawing, but also of a whole bunch of other engineering data.

Could you put that now into the context of — say — some of the challenges that engineering or product development teams have with respect to these $2 \mathrm{D}$ and $3 \mathrm{D}$ objects?

RB: Yes. I'm going to take some of the data from a survey that we commissioned lately from Harris Interactive. We commissioned a survey and Adobe was not recognized as a sponsor so people could speak very freely. We found their challenges in some of this data. CAD users and other technical users realize or know the benefits of collaboration and capturing design flaws earlier. Sharing data much earlier in the design phase gets you higher quality. But these constituencies were not realizing these benefits. They knew of the benefits, but they were struggling.

The survey really brought out that most people were dissatisfied with the whole way that they were sharing data and collaborating. Some of the data that we got back was that it was taking too long for reviewers to get back to them. Or the comments that they were receiving were just too cryptic. Sometimes they were receiving comments on paper. They wanted to keep everything in a digital workflow.

In some cases, they wanted to share this $2 \mathrm{D}$ and $3 \mathrm{D}$ CAD data, but this CAD data is just so large, in terms of file size, that it's just not easy to transmit across e-mail. So there were many different challenges that I've just described around sharing this product data with a broader audience.
CAD data is too big to share. I've got some IP concerns so I don't want to share my CAD data beyond my firewall. People don't have similar tools and technology to mine, so when I send them something, they can't even open the file - much less take a look at it.

All these challenges were really bogging down the whole communication and collaboration process.

MM: Rak - it seems to me that there are two very distinct modes of communicating and interacting within a design team. One is, it tends to be really more focused on ideation and creation. That's much more of a circular, collaborative process of discovering what's missing or needed. Then once you're certain that it's going to be a widget of XYZ dimensions, then it tends to focus on more of a procedural, step-by-step gated workflow.

There seem to be two underlying social patterns in there. One's the circular collaborative process and the other one's more of a linear procedure where things are passing or not passing. Could you speak to some of the challenges that you've seen in both of those modes, as they relate to $2 \mathrm{D}$ and $3 \mathrm{D}$ items?

RB: Sure. I'll do my best to address your question. You may have to be more specific. But let me see if I've got it.

Again, it really comes down to, "How does the engineering group that's authoring all this CAD data share all this great information with a broader constituency?" Whether it be marketing people or procurement people, we ultimately have to source all this material from suppliers. We need to get it manufactured.

People need to know information. So the challenge has always been, "How do I place all this product data and all this information in a consumable way that anyone can consume?" Regardless of the technology they possess. Regardless of the skills that they have.

Procurement people have different skill sets than marketing people. And marketing people have different skill sets than manufacturing engineers. That becomes the challenge. In the ideation process, how do I involve more people in this process, so I can get the best product design?

Have I addressed those challenges? Have I addressed your question?

MM:Yes. 
One of the other aspects of collaborating in the design and manufacturing process often entails going out to your suppliers who then have to come back and negotiate the design. Usually either on the basis of performance, cost, suitability of the material and so on.

I'm assuming that Acrobat 3D supports that kind of backwards-and-forwards negotiation of the design. If so, could you explain how that works? RB: Sure. First and foremost, let's take a look at today's whole global economy. We're all working in a very globally extended environment, where your suppliers are no longer right next door to you, or even in the same state as you. They're more likely to be in a different time zone and in a different country.

The challenge now is, "How do I work with my suppliers - even in the early onset of the design?" A lot of the expertise around product design lies in the supplier base. "How do I get the best seat design for my automobile? How do I get the best fender? How do I get the best engine?" All that data lies outside in the supply chain.

Yet the challenge has always been, "How do I collaborate more effectively?"

MM: As an actual fact, Rak, I would dare say that most of the good stuff that a product manager or an engineering team would want to know does not actually exist as data. It exists more as tacit knowledge or tacit information. Unarticulated. Unspoken until someone actually - an expert - is asked, and then responds to a question.

That kind of gets to more of what I'll call not so much "data," which tends to be structured, but more unstructured, almost conversation-like threads associated with the nuances or implications of the explicit aspects or features or properties of a design or design package. RB: Could you be a little bit more specific? MM: Yes. Could you speak then to some of the challenges that you and your customers have seen in terms of structuring a conversation with the idea of eliciting this tacit information?

RB: Yes. Clearly, a lot of intellectual knowledge resides in peoples' heads. That's what you're paid for. To take your intellectual information and create better products. But typically, that goes on whether it's face-to-face meetings or web conferences or sharing of documents.

Basically you have to elicit lots of different conversations with suppliers and customers, as well as partners, to get the right product created. The challenge has always been that while back in the 1970s and 1980s - it used to take three years to get a product to market; nowadays companies have about 18 months to get the product to market.

It's really critical that companies meet and collaborate - whether it's face-to-face, e-mail, web conferencing - all of that has to take place. I hope I've addressed your question, there. MM: Sure. Could you share with us how the Acrobat 3D file object works in some of these collaborative environments like Adobe Connect or Breeze?

RB: Sure. Back to this Harris Interactive survey that we commissioned. We found that a lot of customers still are getting on planes and jumping on trains and traveling face-to-face. But clearly, with all the cost-reduction challenges that our customers face, web-conferencing is really becoming a more popular way of meeting faceto-face, without leaving your office. That was borne out in this survey. Still, face-to-face travel still remains very popular. E-mail remains popular.

Acrobat Connect allows customers to freely exchange ideas - either through using web cameras or by exchanging documents and interactively - in real-time - marking up documents and getting everybody's ideas on the table very rapidly. That's one of the benefits of Acrobat Connect from a web conference point of view. Not only can you collaborate, but once your product has actually started formulating and is about to hit the market you can use Connect for some rapid training of your salesforce and field technicians. Even customers, if it makes sense.

All the way from the ideation of your product to the serviceability of your product, Acrobat Connect and web-conferencing allow you to have that face-to-face contact and share ideas.

MM: You've introduced now the notion or underlying idea of product lifecycle management. Specifically, managing not just the engineering of documents, but managing or facilitating the conversation about a product through its lifecycle. From ideation all the way through service and training, and perhaps even upgrade or retirement.

Could you speak to the notion, then, of this lifecycle? A product lifecycle living in a 
collaborative supply chain? What are some of the things that you've seen either in terms of customers or industry trends in this notion of a digital supply chain that spans a product lifecycle?

RB: If you take a look at the different phases of a PLM in process - and I'll call it a process. Right? It's not a product you buy, but rather it's a process. From the sheer idea or the planning of the product starting into design, moving into sourcing, manufacturing, selling, serviceability and then retiring it. So that's the whole spectrum of the PLM environment.

As I said earlier, the expertise really lies in the supply chain in many cases. Specifically in automotive and aerospace. There's tremendous knowledge out there in how to design specific aspects of a product. So it's really incumbent upon OEMs that are taking products to market to involve their suppliers much earlier in the design phase. Whether it's in the early planning phases of how much this product is going to cost and how to reduce its footprint or weight.

How it fits within the envelope of our product.

Suppliers need to get involved really early. Not just in the manufacturing of the final product, but in the initial onset of the idea of how to take this product to market. To make it lighter and make it better and make it cheaper.

Then in the design phase, as we move from planning to design, a lot of this design gets outsourced. Then you've got to look at, "How do I communicate all these different designs with a broader audience?"You can't always share CAD data. That's really where Portable Document Format (PDF) comes in handy, in that you can share the different versions of your product design with a larger constituency that may or may not have CAD applications or technical expertise.

Then as you move into the sourcing or procurement phase, that's really where supply chain management is so critical. Suppliers are now really having a huge impact on costreduction issues and profitability. If you look at an example here of Boeing and Airbus, due to lack of material resources that are available in the supply chain their final product - their airplane — is now going to be delayed by X-number of months because of supply chain issues.

Then you get into manufacturing and selling. In every aspect of the PLM process, the suppliers are integral and very critical to taking your product to market. Does that answer your question?

MM: Perfect.

This also then introduces the idea of how Adobe uses its XMP and other facets of its Acrobat family to capture a lot of that metadata and/or job-description data that may be part of a particular supplier/vendor or supplier/ customer interaction.

Can you just give us a quick reprise of how you see or how you've seen customers in these $2 \mathrm{D}$ and $3 \mathrm{D}$ workflows of the manufacturing supply chain? Can you take us through a couple of use cases or examples of kinds of metadata that people are putting into or associating with these 3D objects?

RB: Sure. More and more, customers want to really reduce their need or reliance on creating the $2 \mathrm{D}$ drawing that goes along with the $3 \mathrm{D}$ design. In many industries, $3 \mathrm{D}$ is that master model. That's what you want to do your stress analysis on. It's the same model that you want to do your manufacturing from. It's the same model you want to build your tooling from.

It's really critical that we put all the information right onto that model. Including what we refer to as geometric dimensioning and tolerance. Sometimes it's referred to as FT\&A.

Feature tolerance and annotation.

More and more of the CAD vendors are starting to put this type of capability to enable CAD users to put dimensions right on the 3D model, and not have to wait for the 2D process. To put the critical manufacturing information - as to what is the tolerance of this particular hole or this particular dimension. To put all the different texts and annotations associated to it.

Then once again, as I said - the challenge... MM: In a sense, Rak, what you're talking about - if I could summarize it this way... The 3D drawing is actually now a database. It's a database of information as it relates to the $3 \mathrm{D}$ object. So now we're talking almost like a portable database. $\mathbf{R B}$ : Yes. It's like a database. But the 3D model has always had all of that intelligence already. Now we can document all the critical manufacturing metadata - if you want to call it that - in terms of dimensions, tolerances, annotations - as well as other metadata. Like, "Who was the supplier? What type of material am I going to use for this? What revision of the CAD model are we in?" 
It's really important that everybody understands not just the 3D model, but understands all the geometric dimensions and tolerances and other metadata. Like material. Revision and so on and so forth.

MM: We've been talking a lot about productoriented 3D objects. I'm sure that you probably have some examples of things that are more like game designs or $3 \mathrm{D}$ environments. Things that are not necessarily products, but could be anywhere from entertainment to architectural renderings to other things. Things that might be curriculum in a physics class or something.

Could you speak to some of the other kinds of objects that you've seen customers put into Acrobat $3 \mathrm{D}$ ?

RB: What a great question, Michael. We're really seeing a tremendous amount of adoption of 3D PDF, as more technical users start to share their design information in PDF. Beyond just that normal discrete manufacturing customer - the automotive, aerospace and defense area.

We've got customers who are sharing consumer goods like bicycle designs or food processors in PDFs. They're using it in education as well - to educate their students.

One example that I've actually seen is in the dental industry. Just showing 2D bitmaps or sharing it with a book of a dental implant or how teeth work just wasn't working for a particular class of teachers. So they started using Acrobat 3D and bringing in 3D models that they had scanned of peoples' dentures or teeth, and using that for curriculum.

I've seen examples of sharing how a heart works, and all the chambers of a heart in 3D PDF. It's just simply amazing, the level of 3D data that's coming out, beyond just our normal perception of creating technical documentation for some mechanical widget.

People are using PDF to talk about heart chambers. They're talking about exposing dental work, for example. There are so many different use cases that we're seeing beyond just the normal. MM: I would imagine, Rak, that you also have seen applications of this in what we'll call dynamic or 3-dimensional user manuals?

Yes. Very much so.

MM: Could you speak to that and what some of the things are that you've seen there? RB:Yes. A great customer of ours, Eaton Corporation, was using Acrobat Professional for a while. When they saw what Acrobat 3D could enable them to do, they started using Acrobat 3D.

By leveraging PTC — Parametric

Technologies Corporation - or proengineering content from engineering into their technical publications, which they...

MM: Their windchill product - yes?

RB: As well as their CAD product called Pro Engineer Wildfire.

MM: Right.

RB: The technical publishing group was able to leverage all of this CAD data into their technical publications that were normally shared with their repair technicians for these uninterruptible power systems that they had. They got really tremendous feedback from their repair technicians that these people who only had the free Adobe Reader... These repair technicians could easily now navigate and better comprehend the object - the system that they were going to be servicing.

Eaton Corp also told us that they reduced some of their costs in printing and delivering all of these manuals. Now everyone could just consume all of this data - this whole publication - through the free Adobe Reader.

The third benefit they realized was that they could receive digital comments from their repair technician. Giving them feedback on how to improve the manual. So not only did they incorporate 3D, but it made it easier to understand. They saved costs on printing and were able to communicate more effectively with their repair technicians on how to improve their repair manuals.

MM: So built into the 3D PDF would be some sort of messaging function that a user could message back textual or audio notes to the mothership?

$\mathbf{R B}$ : Certainly PDF is what we call the supercontainer of information. It cannot only take 2D and 3D data, but it can take audio and video files. It can take just about everything that you throw at it. Eaton Corp was receiving actual markups from their repair technicians. The comments.

They'd just use the Adobe Reader and say, "Page 22, Paragraph 3. Right here." They'd circle it with a cloud or something. They'd say, "This doesn't make sense. Can you please clarify?"

They weren't, to my knowledge, necessarily sending audio or video files. Rather, they were 
marking up the document and sending it back to the authors for improvement.

MM: You know, Rak, this reminds me of a passage in a book by John Seely Brown published a number of years ago. It was called "The Social Life of Information." A brilliant book.

John Seely Brown at the time was the CTO of Xerox. Head of Xerox Parc. He was most interested in why Xerox, Docutec service people - why the field service people - were not using the manuals. More specifically, what was it about the manuals or the texts that the two of them didn't get together?

He then instituted a very long — almost ethnographic — study of field techs. He discovered that the techs would get together before the start of the day for coffee - midmorning coffee - lunch and after-work drinks or whatever. They'd come together - four or five in a kind of ad hoc user group - and they'd share cribbed notes and insights. They'd kind of muse out loud in terms of the implications of this or that phenomena.

He discovered that probably 80 or 90 per cent of the knowledge in terms of problem solving, or what I like to call "Solutioneering knowledge," really existed in that informal tacit conversational discovery of practitioners coming together. Asking questions almost in a Socratic dialogue kind of way. Understanding that no one individual knew the right answer, but somehow collectively a new insight would emerge.

It seems to me that what John Seely Brown went into was the thing he wanted to bottle or capture. I think he went down a dead end, vis-àvis expert systems. Because expert systems are never really able to model the human context.

That said, it seems to me that the next wave or forward-looking notions as far as Acrobat 3D is that it's really a facilitator for that kind of collaborative problem-solving conversation that's more about discovery than it is about redo. In terms of traditional conveyance of information.

Could you speak in more of a forwardlooking fashion, of how you envision 3D Acrobat being much more a part of the knowledge work economy and the collaborative spirit of what I refer to in John Seely Brown's Xerox Tech Academy of Peers?

RB: Sure.
There is so much information that our knowledge worker constituency wants to share. It's a question of sharing it in a clearer, more concise way. That's really where we want to help our customers navigate through PDFs. Better be able to share data with all of the people that can consume it.

Rather than just putting lots of different pages together into a PDF, wouldn't it really be efficient if we provided our authors of the PDF a way of creating a very polished look and feel? Maybe even incorporating a whole multimedia aspect into a PDF?

Rather than just delivering them $2 \mathrm{D}$ and $3 \mathrm{D}$ and technical specifications, to improve the user experience and how they navigate through the PDF.

Whether it's through Flash or through audio and video - bringing Flash and PDF together, to really create a more engaging experience for the people who consume this PDF.

MM: So, Rak - you're really introducing two ideas here. I'd like to more fully develop these.

One has to do with the idea of putting multimedia objects inside the PDF container. For example, you can put a Flash animation or video in a PDF and it will play. The second thing has to do with the next wave of innovation and creativity. Not being so much what we put into the PDF, but how we navigate these PDFs almost as a virtual world. To really develop much better navigational schemes and usability schemes for this burgeoning - if not manifolding - amount of content that's inside the PDF.

Could you speak to either of those two? RB: Sure. I will.

You have to remember what our Adobe mission and our whole culture is about. It's really about providing a very engaging experience for not only the author, but also the consumer of all of that data.

Let's take a look at the multimedia experience with a PDF. Imagine, if you will, that I'm sharing some 3D data. Whether it's for sharing and collaborating or maybe it's even just a technical publication that I'm putting together - like a repair manual.

I've got this 3D data, and I may even want to put - as the author — some hotspots in specific areas. So that when you click on that particular part of the graphic, a video could 
appear. To say, "This particular aspect of my part has been developed over ten years." There'd be a whole narration and a video that would come out.

Then, as the consumer of that information navigates through this 3D PDF and clicks on another hotspot, another video comes up. To further that, what we could do - if this were in the educational market - we could create a series of quizzes to further ensure that there was comprehension of the data.

MM: And there's nothing to prevent that hotspot from linking outside to a destination on the web?

RB: Of course not. Exactly. We can marry 3D with Flash. We could put audio-video into particular hotspots if it makes sense. When you click on a hotspot, it goes to a hyperlink to another website. The possibilities are endless. That's really where we're bringing the conversation full circle, here. All of these creative ideas are in the minds of all these smart engineers and marketing people. Right?

It's really unlimited as to how you can create a more engaging experience for yourself the author - but also for the consumer of all of this data.

MM: There are two more items I'd like to get into, Rak. One is the notion of user-generated content or "social media." We've continued to read about all the new developments and facets of social media. But specifically where users start creating content or start to interact with other users. It creates almost a parallel set of content and/or conversations.

How have you seen that social dimension? The user-generated content or user-generated insights? How have you seen or how do you envision that becoming part of this overall Acrobat process or workflow?

$\mathbf{R B}$ : If we just step out of the realm of the 3D world - PDF is really the de facto standard in the way people communicate and collaborate with each other. It has been for many years.

Whether you're a human resources person or a marketing person or whatever, you can use PDF as a way of gathering all this data. Whether it's a social interaction, I can't speak specifically to that. But it's a way of gathering a community around some ideas that one or a team of people have.

PDF becomes the way of aggregating all of those comments from your network of people.
I'm not sure if I've answered your question correctly. Please let me know.

MM: That's good enough.

One of the other things I'd like you to speak to in the remaining time that we have here, Rak, is the notion of a policy-managed content or a policy-managed workflow. Highlighting the idea that as a PDF moves through an organization or through a supply chain, the owner of that PDF can link all or portions of the content to a policy server, thereby controlling certain access paths or printability or viewability of the item - based on a permissions granted or not. Could you speak to that?

RB: Sure. Michael, if you'll permit me, I'll talk a little bit about some of the challenges that we're hearing - either through surveys that we've commissioned or customers we've engaged with.

It's amazing how digital rights management is becoming mission-critical to large companies and way down to small consultants, because of all this intellectual property that's flying around in the ether. If it falls into the wrong hands, there's been case study after case study — and you hear it in the news all the time... A disgruntled employee shares all his confidential company data. It wasn't secure. Everybody got access to either databases or design data.

Companies lose billions of dollars as a result of not protecting their data.

We've also heard from customers that at the engineering level, they want the ability to restrict the ability to view a PDF - if and when they choose. Let me give you a real-world example.

Here's a Request for Proposal that a procurement manager put together. He's going to put together a bid package. He's going to put some 3D content into a PDF. He's going to put an interactive form that the suppliers can fill out and bid with. He's going to put some technical specifications all into a single PDF and send it out to 20 different suppliers. Let them bid on it.

Eventually, somebody's going to win that bid. All of this $3 \mathrm{D}$ content is very sensitive information. It's still out there. What if the procurement manager had a method that he could revoke privileges for viewing those PDFs to those suppliers who did not win the contract?

That's really where the rights management technology from Adobe is responding to our customers' needs. 
Within the LiveCycle family of products we have a solution called LiveCycle Rights Management for the Enterprise Suite. That really meets our customers' abilities and needs to protect their sensitive information. It really plugs up any security leaks. Just as I said earlier one aspect of this solution is the ability to essentially put a tether to any PDF that you send out there beyond your firewall. To be able to revoke privileges or add privileges.

Let's say I send a bunch of people a PDF and I forget to add printing capabilities to Michael's feature set. At any time - even after that PDF has been sent out - I can add privileges. I can also revoke privileges and say, "Time has passed. I don't want anybody to be able to print. I don't want anybody to copy the document. Or, for that matter, open the document."

It really helps our customers have much greater confidence in the way they share some sensitive information and collaborate with their supply chain beyond their firewall. That really impacts their whole business process, because they get total control now of who can see the document - for how long - and what they can do with the document.

That briefly covers what the whole rights management field is all about, and why our customers are caring about it so much.

MM: Fabulous.

Are there any final things that you'd like to conclude on, in terms of the roadmap or some of the things that users have requested that Adobe responds, "Yes. We get it. We understand. Look forward to us addressing that in some way."

RB: I've got to say that we're continually engaging with our customers. Whether that be through our surveys or through our direct salesforce talking to the larger OEMs. Across all industries. Whether it's manufacturing, healthcare, pharmaceutical, financial services or government. We're continually asking them how we can provide technology to benefit them better. "How can we help you create better solutions - better transactions - within your organization?"

Within Adobe, that's what we're really focused in on. Whether it be the Acrobat family - whether it be the LiveCycle family whether it's Flash or web conferencing. We're really focused in on how we can make our customers' experience far more engaging and far more productive.

We're continually pushing the envelope. How do we integrate all of this differently? How do we spread it everywhere?

This is an exciting time at Adobe, in trying to take all of the technology that we own whether it's in the Acrobat business or outside my business unit - and really take it to market more effectively for our customers.

MM: Fabulous. Rak, I want to thank you for this interview. Great success with the Acrobat 3D.

RB: It's been my pleasure, Michael. Thank you for your time. 